\title{
THE ROLE OF PERSONAL NORM IN PREDICTING INTENTION FOR DIGITAL PIRACY
}

\author{
Godwin G. Udo, University of Texas at El Paso,gudo@utep.edu \\ Kallol K. Bagchi, University of Texas at El Paso, kbagchi@utep.edu
}

\begin{abstract}
This study employs the Norm Activation Model (NAM) to examine the factors that influence digital piracy (DP). NAM is a well-grounded, attitude-based model that proves to be an effective predictor of the motivation and the role of emotions, which drive behavioral intentions. With data from 231 participants and using PLS, the results show that all three independent constructs have a significant impact on personal norm, which in turn influences pirates' intention to engage in DP. The role of social influence on the pirates' intention to continue to practice DP is significant as well.
\end{abstract}

Keywords: Digital Piracy, Personal Norms, Prosocial Intention, Social Influence, NAM

\section{INTRODUCTION}

As digital economy matures globally, digital piracy (DP) has gained in popularity as a topic of great concern among companies, governments, academicians, and in social media. Several technologies and techniques are now in use to check the ever-increasing growth rate of DP. A number of studies attempt to explain the phenomenon or to expatiate the reasons for its growth and how to curtail it. According to Bagchi et al. (2006), the driving force behind DP includes economic, low infrastructural development, lack of regulatory enforcement, and social or cultural. Despite the amount of efforts by vendors and researchers to put spotlight on issues of DP, very little is still known about it (Bhattacharjee et al., 2006). One area of DP that is most lacking in terms of research effort is the social and psychological aspect (Taylor et al., (2009). There is a need for research approach that employs psychological models to examine DP behaviors. One such model, which has been used in other types of behavior, is Norm Activation Model (NAM). The NAM model theorized that the personal norms are influenced by two major factors: Awareness of Consequences (AC) and Ascription of Responsibility (AR). AC is being aware that performing (or not performing) a certain behavior can lead to certain outcomes or consequences. AR is the feeling of responsibility for performing a certain behavior.

The present study uses NAM to explain the DP behavior with the aim of extending the understanding of the underlining factors driving DP. Using NAM theory to explain DP is a contribution that could be beneficial to vendors and other intellectual property owners. Knowledge of a prosocial behavior is a new effort in the containment of DP given that it identifies the factors that are associated with DP from normative perspective. Such understanding can help in policy formation for the management of DP problems.

\section{NAM AND DIGITAL PIRACY (DP)}

Schwartz (1977) offered the concept of Norm Activation Model (NAM), which he used to demonstrate that donating to charity or working to keep the environment clean is a prosocial behavior that is driven by personal norm of an individual exhibiting the behavior. According to the NAM model, prosocial behaviors emanate from personal norms $(\mathrm{PN})$, which govern a sense of moral obligation to engage in or abstain from certain behaviors. Since this study, several authors have employed the model with various behaviors such as pro-environmental actions, individual energy consumption, blood donation, volunteering, etc. (Aronson et al, 2005; Batson and Powell, 2003; De Groot and Steg, 2010). Figure 1 is a classic NAM that shows the relationships among AC, AR, PN and behavioral intentions. In this research, we demonstrate how this model can examine and explain digital piracy intentions.

Figure 1 illustrates NAM as used in the present study. The basic NAM shows how the relationships among AC, AR, and behavioral intention is mediated by PN (Steg and De Groot, 2010). In other words, PN is activated when an individual acknowledges that acting prosocially will lead to positive consequences for other individual (i.e. Awareness 
of Consequences) and when that individual feels responsible for the negative consequences that could result from his/her failure to act (i.e. Ascription of Responsibility).

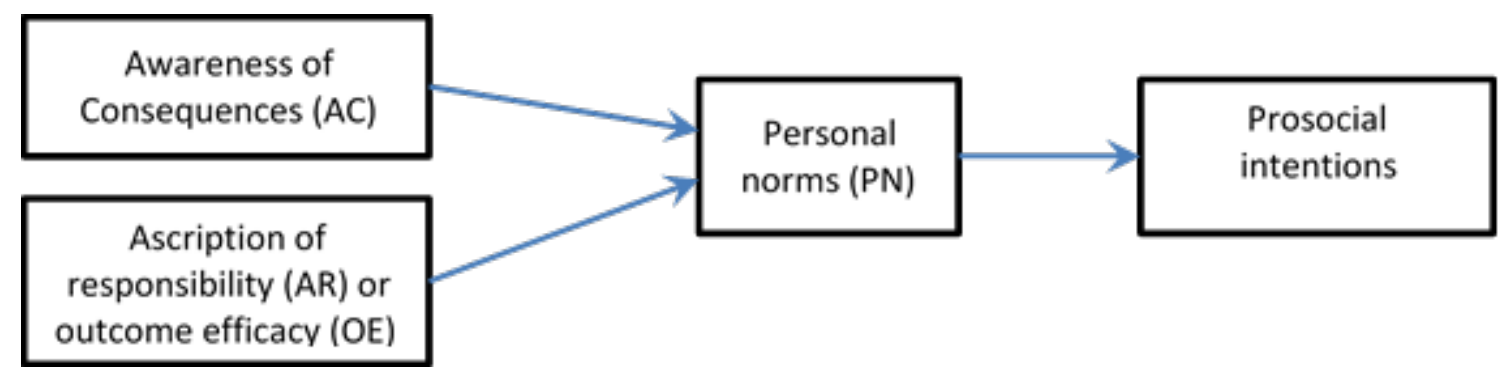

Figure 1. The Norm Activation Model

In past studies, NAM has been shown to capture or explain major societal events such as environmental concerns or blood donation all of which are positive actions. In the present study, we believe that the model can equally explain a negative or aggressive action such as DP. Onwezen et al., (2013) seem to have the same view when they used NAM to examine the effects of pride (which results from positive actions) and guilt (which results from negative actions) on intentions. Their results indicated that both desirable and negative emotions have significant impacts on personal and social norms, which in turn positively or negatively affect behavior respectively. In the present study, we attempt to simulate DP as a negative behavior or counter-prosocial behavior, which makes it suitable for the NAM.

\section{THE RESEARCH MODEL AND HYPOTHESES}

The models used in the study of DP across social science disciplines (Taylor et al., (2009) are mostly cognitive and consequentialist in nature. For that reason, these models have limited explanatory power when applied to such psychological issues as digital piracy. Attitude-based models seem to perform better in such cases because they account more fully for the motivation and the role of emotions which drive behavioral intentions (Taylor et al., (2009). Trafimow and Finlay (1996) surveyed the literature and discover that out of 30 studies, twenty-nine demonstrated that attitude is a good predictor of intention. Peace et al., (2003) specifically conclude that attitude is the best predictor of intention to pirate software. Since NAM is an attitude-based, we suspect that it has a potential to better explain the factors affecting DP.

Awareness of Consequences (AC): is one of the two main factors in NAM and reflects the ability of an individual to be aware that performing (or not performing) a certain behavior can lead to certain outcomes or consequences. Several studies (De Groot and Steg, 2009; Bamberg and Moser, 2007; Peters, et al, 2011; Huijts, el al., 2013) indicate that AC positively affects personal norm (PN). De Groot and Steg (2009) used three separate studies (energy policy, car use reduction, and construction of distribution centers) to show that $\mathrm{AC}$ has a positive effect on PN. Also, Huijts, el al. (2013) find AC to be significant variable that explains PN in a study that used NAM to examine the intention of people to demonstrate against building hydrogen plants which have negative effect on the environment. Specifically, we predict that the more people are aware of the consequences of DP, the more their personal norm will be influenced. The AC-related hypothesis for the study, as shown on the proposed model, is:

$\mathrm{H}_{1}$ : Awareness of Consequences of DP has positive impact on the Personal Norms of digital pirates.

Ascription of Responsibility (AR): is defined as the feeling of responsibility for performing a certain behavior. Schltz, et al., (2005) document the effect of AR on PN in their study of environment. The participants were asked to indicate how serious were each of the six environmental problems and their findings indicate that AR has a positive effect on PN. The study conducted by Steg and De Groot (2010) also leads to the same conclusion that AR influences PN in a positive way. With regard to the present study, we predict that if people have strong feeling of responsibility toward DP practice, their personal norm may be positively influenced but if they have no feeling of responsibility their PN will be unchanged toward DP. Therefore, our AR-related hypothesis is as follows: 


\section{Issues in Information Systems}

Volume 20, Issue 4, pp. 181-187, 2019

H2: Ascription of Responsibility for DP has positive impact on the Personal Norms of digital pirates.

Social Influence (SI): Venkatesh, et al., (2003) describe SI as the degree to which a person perceives it is not socially acceptable to use a certain technology. SI could be the individual's perception of his/her employer's, colleague's, or customer's opinion of his/her technology adoption and use (Venkatesh and Morris, 2000). It is the degree of attention an individual gives to his/her referral groups (Hsu and Lu, 2004). Some authors have investigated the effect of SI on IT adoption and have come to the same conclusion that it has a significant influence (Eckhardt et al., 2009). This influence could enhance the motivation to (or restrain from) using the technology in question. In the case of DP we argue a strong social influence may lead to a more positive personal norm and a less pro-social intention to engage in DP practice. Accordingly, the following SI-related hypotheses are presented:

H3: Social Influence has positive impact on the Personal Norms of digital pirates.

H4: Social Influence has negative impact (i.e. discourages) on the intentions of digital pirates.

Personal Norms (PN): is described by Schwartz (1977) as "feelings of moral obligation to perform or refrain from specific actions." PN is activated when an individual acknowledges that acting pro-socially will lead to positive consequences for other individual (i.e. Awareness of Consequences) and when that individual feels responsible for the negative consequences that could result from his/her failure to act (i.e. Ascription of Responsibility). In effect, if the individual's norms are not activated, his/her actions (or no actions) will be judged as appropriate and so no prosocial action will take place. PN is therefore the mediator in the relationship between AR or CA and prosocial intentions which leads to actual behaviors. In the present study, PN is interpreted as the moral obligation people may feel that makes them engage or refrain from DP. Those with little moral feelings will be more engaged in DP than those with strong feelings. Some authors (Schwartz, 1977; Huijts, el al., 2013) have established a significant positive relationship between PN and prosocial intentions. These authors have shown that PN guides behavioral intention. In fact, Huijts, el al. (2013) maintain that PN is the most important predictor of intention to act pro-socially. It is worth noting that personal norms are different from social norms. Social norms are activated and sustained by the external environment whereas personal norms stem from the inner person of the individual.

The PN-related hypothesis can be stated as:

H5: The Personal Norm of digital pirates has negative impact (i.e. discourages) on their intentions to engage in DP.

\section{METHODOLOGY}

\section{Instrument}

Our proposed research model is based on literature review of previous studies and grounded on the theory of NAM. We developed a survey instrument based on current relevant literature in addition to modifying existing survey items from previous studies. The items that capture the three factors were taken from Steg et al., (2005) and Cronan and AlRafee (2008). A seven-point Likert scale was used to capture the constructs of variables in the study: strongly disagree to strongly agree Likert scales. Factor analysis shown in Table 1 is satisfactory. Cronbach's alpha, which indicates the reliability, for the AC scales is modest at 0.793 while the composite reliability is 0.780 (see Table 2). From Table 2 it can be seen that the measuring instrument has the required validity and reliability since the Cronbach's alpha for all the study variables range from 0.699 to 0.962 while the composite reliability ranges from 0.778 to 0.964 . The variance inflation factor (VIF) is also at acceptable level for each variable,

\section{Procedure}

Two hundred and fifty undergraduate students from a large Southwest U.S. University were asked to participate in this study. All the participants were informed that participation was voluntary and that only the aggregated results will be published with no indication of individual participants. Students were instructed not to take part in the study if they had no experience with DP. A total of 231 student responses were eventually used in the final analysis, due to missing data and non-response. The non-responses bias was not detected in a separate test conducted for this purpose. Majority of the students were between the ages of 20-30 (with average age $=25.9$ ), and the percentage of females was $65 \%$. 
Table 1. Cross-Loading Matrix

\begin{tabular}{|c|c|c|c|c|c|}
\hline & $\mathbf{A C}$ & $\mathbf{A R}$ & $\mathbf{P N}$ & $\mathbf{I N T}$ & SI \\
\hline AC1 & $\mathbf{. 9 6 5}$ & -0.188 & 0.068 & -0.112 & -0.046 \\
\hline AC2 & $\mathbf{. 8 8 3}$ & 0.078 & -0.141 & 0.238 & 0.018 \\
\hline AC3 & $\mathbf{. 9 4 0}$ & -0.117 & -0.241 & -0.020 & 0.122 \\
\hline AC4 & $\mathbf{. 9 3 2}$ & 0.174 & -0.172 & 0.105 & 0.106 \\
\hline AR1 & .158 & $\mathbf{0 . 8 7 6}$ & -0.213 & 0.258 & 0.212 \\
\hline AR2 & .127 & $\mathbf{0 . 8 6 6}$ & -0.184 & 0.285 & 0.204 \\
\hline AR3 & .268 & $\mathbf{0 . 5 3 9}$ & -0.363 & 0.456 & 0.367 \\
\hline PN1 & -0.039 & 0.040 & $\mathbf{0 . 9 1 9}$ & 0.267 & -0.069 \\
\hline PN2 & -0.060 & 0.099 & $\mathbf{0 . 9 3 3}$ & 0.204 & 0.003 \\
\hline PN3 & -0.076 & -0.029 & $\mathbf{0 . 9 7 7}$ & -0.005 & 0.098 \\
\hline PN4 & 0.113 & -0.050 & $\mathbf{0 . 9 6 8}$ & -0.028 & -0.084 \\
\hline PN5 & -0.011 & 0.040 & $\mathbf{0 . 9 8 7}$ & 0.011 & -0.117 \\
\hline PN6 & -0.066 & 0.163 & $\mathbf{0 . 9 7 6}$ & 0.042 & 0.027 \\
\hline INT1 & -0.013 & 0.020 & 0.082 & $\mathbf{0 . 9 8 1}$ & -0.056 \\
\hline INT2 & -0.048 & -0.008 & 0.025 & $\mathbf{- 0 . 9 7 9}$ & -0.002 \\
\hline INT3 & -0.003 & -0.009 & -0.031 & $\mathbf{- 0 . 9 9 6}$ & 0.023 \\
\hline SI1 & 0.065 & -0.191 & -0.076 & 0.013 & $\mathbf{0 . 9 5 6}$ \\
\hline SI2 & 0.016 & 0.021 & -0.040 & -0.005 & $\mathbf{- 0 . 9 1 6}$ \\
\hline SI3 & 0.063 & 0.060 & 0.036 & -0.126 & $\mathbf{- 0 . 8 7 3}$ \\
\hline SI4 & -0.091 & -0.100 & 0.144 & -0.087 & $\mathbf{0 . 9 7 6}$ \\
\hline
\end{tabular}

Table 2. Summary of Loadings, Reliability and Validity

\begin{tabular}{|c|c|c|c|c|c|c|}
\hline Construct & Items & $\begin{array}{l}\text { Standardized } \\
\text { Loadings }\end{array}$ & $\begin{array}{l}\text { Composite } \\
\text { Reliability }\end{array}$ & $\begin{array}{l}\text { Cronbach's } \\
\text { Alpha }\end{array}$ & $\overline{A V E}$ & VIF \\
\hline $\begin{array}{l}\text { Awareness of } \\
\text { Consequences (AC) } \\
\text { (4 items) }\end{array}$ & $\begin{array}{l}\mathrm{AC} 1 \\
\mathrm{AC} 2 \\
\mathrm{AC} 3 \\
\mathrm{AC} 4\end{array}$ & $\begin{array}{l}.965 \\
.883 \\
.940 \\
.932\end{array}$ & .780 & .793 & .697 & 1.301 \\
\hline $\begin{array}{l}\text { Ascription of } \\
\text { Responsibility (AR) } \\
\text { (3 items) }\end{array}$ & $\begin{array}{l}\text { AR1 } \\
\text { AR2 } \\
\text { AR3 }\end{array}$ & $\begin{array}{l}.539 \\
.876 \\
.866\end{array}$ & .736 & .898 & .436 & 1.194 \\
\hline $\begin{array}{l}\text { Personal Norms (PN) (6 } \\
\text { items) }\end{array}$ & $\begin{array}{l}\text { PN1 } \\
\text { PN2 } \\
\text { PN3 } \\
\text { PN4 } \\
\text { PN5 } \\
\text { PN6 }\end{array}$ & $\begin{array}{l}.919 \\
.933 \\
.977 \\
.968 \\
.987 \\
.976 \\
\end{array}$ & 903 & .888 & .782 & 2.247 \\
\hline $\begin{array}{l}\text { Social Influence (SI) } \\
\text { (4 items) }\end{array}$ & $\begin{array}{l}\text { SI1 } \\
\text { SI2 } \\
\text { SI3 } \\
\text { SI4 }\end{array}$ & $\begin{array}{l}.981 \\
.979 \\
.974 \\
.956\end{array}$ & .862 & .814 & .784 & 1.696 \\
\hline $\begin{array}{l}\text { Prosocial Intentions } \\
\text { (INT) ( } 3 \text { items) }\end{array}$ & $\begin{array}{l}\text { INT1 } \\
\text { INT2 } \\
\text { INT3 }\end{array}$ & $\begin{array}{l}.993 \\
.999 \\
.992\end{array}$ & .964 & .962 & .984 & 2.380 \\
\hline
\end{tabular}




\section{Issues in Information Systems}

Volume 20, Issue 4, pp. 181-187, 2019

\section{RESULTS}

WarpPLS 4.0 was used to conduct PLS modeling. The proposed model fit and quality indices are within the recommended values, each meeting or exceeding the acceptable level of a good fit. For example, the study's statistical suppression ratio (SSR) is 1.0 whereas WarpPls 4.0 ranks a model as acceptable if the SSR is greater than 0.70. A confirmatory factor analysis (CFA) indicates that all items used in the final analysis loaded at acceptable levels (Chronbach $\alpha>0.70$; Nitse, et al., 2004) on the seven major independent variables and the two dependent variables (INT and AB) as shown in Table 1. The Covariance Analysis of Linear Structural Equations (CALIS) procedure in WarpPLS 4.0 was used to test measurement reliability (Ringle, et al., 2005). The construct validity is ensured by the convergent and discriminant validities. In this study, both convergent and discriminant validities were observed to meet the criteria.

As indicated on Figure 2, the R-square values for Personal Norm and Intentions are 0.51 and 0.59, respectively. Figure 2 displays the path coefficients and the significant levels. All of the model paths are significant at least at the $\mathrm{p}<0.001$ level. After establishing the adequacy of measurement model, the structural model was next examined to test the hypotheses. All three independent constructs have a significant impact on personal norm or PN, with $\mathrm{R}^{2}$ of 0.51 . All the independent variables have a significant impact on intention in the expected direction $(p<0.001)$. All five hypotheses are supported.

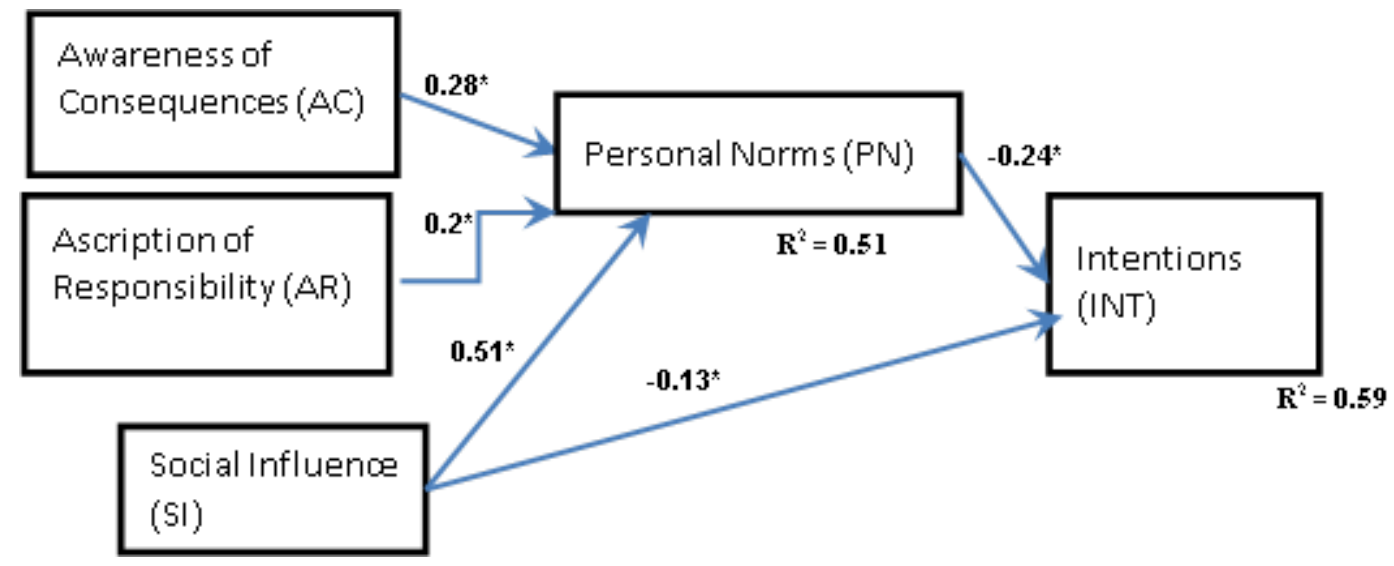

Figure 2. Tested Research Model

\section{DISCUSSION AND CONCLUSION}

The present study aimed at using the NAM to explain the driving forces of DP. We were motivated by the fact that NAM has been shown to explain altruistic behavior such as digital piracy. The results strongly confirm our suspicion. As shown in Figure 2, all five path-coefficients are significant at $\mathrm{p}<0.01$ which support the study hypotheses. The tested model is significant with $\mathrm{R}^{2}$ of 0.59 indicating that NAM can be used to explain the intention to practice DP. As confirmed by previous studies (Huijts, el al., 2013; Steg and De Groot, 2010) awareness of consequences or AC and ascription of responsibility or AR both positively determine pirates' personal norms. Accordingly, $\mathrm{H} 1$ and $\mathrm{H} 2$ are supported by these findings. As a new dimension and also extension to NAM, social influence or SI is found to play two significant roles. SI is a direct predictor of personal norms. The stronger the SI experienced by the pirates, the more positive their personal norms. SI is also a mediator between PN and INT or intention to pirate. The results indicate that SI positively affects the pirates' personal norms, which negatively impact their intention to practice DP. The implication of this finding is that if vendors or the governments find ways to manipulate the AC, AR, and SI for potential pirates with the aim of increasing their personal norms then it is possible discourage or decrease their intention to engage in the practice of DP. Programs that encourage social consciousness of the danger of DP should be instituted and incentives should be provided for people to participate in such programs. 


\section{Issues in Information Systems \\ Volume 20, Issue 4, pp. 181-187, 2019}

We also establish that PN negatively mediates the effect on AC and AR on INT as maintained by the original NAM. That is to say the stronger the PN, the less the degree of intention to practice DP. As shown in Figure 2, the path coefficient between PN and INT is $-0.24(\mathrm{p}<0.01)$. This finding confirms the conclusion reached by previous studies (such as Steg and De Groot, 2010). This finding supports hypothesis, H4 and also provides the answers to one of our research questions. It can be concluded that NAM is as good a tool (if not better) in explaining DP intention as it is with several pro-social events.

The present paper contributes to the understanding of the driving forces of DP within the NAM model. The application of NAM theory to DP provides assistance in the search for a new empirical understanding. This model seems to cover a wider range of factors affecting DP. The research model can be used to formulate policies to reduce DP practices. A contribution to theory and research by the present study is the tested model that is herein proposed. This model is well-grounded in theory. Empirical measurement constructs are also provided. It has increased our understanding of what measure could be effective in curbing DP. The role of social influence on the pirates' intention to continue to practice DP has been added the understanding of this phenomenon. The researchers and policy makers can know target or manipulate SI in order to minimize DP. By establishing a program that internalizes the undesirability of DP among peers and other social value systems, digital piracy could be mitigated in a more acceptable and subtle way. Another approach could be to isolate potential pirates from known pirate who are likely to adversely influence the would-be pirates.

Our future efforts will be explore the influence of culture on the proposed model. It is important to study the interaction between culture and NAM constructs. We also plan to apply socio-technical phenomena or applications to the proposed model. Such socio-technical could include hacking, abuse of IT at work, unethical use of, etc. The main weakness in this study could be the fact that only students participated. It would be nice to survey other groups of people. This weakness is not uncommon in DP research and has even been said to be strength instead of weakness. Previous DP studies (such as Higgins, et al, 2007; Bhattacharjee et al., 2006) used student participants with some authors arguing that younger population, and not older ones, are usually the most noted pirates. The younger population is more skillful, poorer, and has more interests in music, games, and copyrighted apps, among other digital products. As shown in this study by the percentage of participants who claim to practice or continue to practice DP, students seem to be the appropriate group for this study.

\section{REFERENCES}

Al-Rafee, S. \& Cronan. T. P. (2006). Digital Piracy: Factors that Influence Attitude toward Behavior. Journal of Business Ethics, 63, 237-259.

Anderson, J. C. \& Gerbing, D.W. (1988). Structural equation modeling in practice: a review and recommended twostep approach. Psychological Bulletin, 103(3), 411-423.

Aronson, E., Wilson, T. D., \& Akert, R. M. (2005). Social Psychology. Upper Saddle River, NJ: Prentice-Hall.

Bagchi, K., Kirs, P., \& Cerveny, R. (2006). Global Software Piracy: Can economic Factors Alone Explain the Trend? Communications of the ACM, 49(6), 70-75.

Bamberg, S. \& Moser, G. (2007). 20 years after Hines, Hungerford and Tomera: A new meta-analysis of psychosocial determinants of pro-environmental behavior. Journal of Environmental Psychology, 27, 14-25.

Batson, C., \& Powell, A. A. (2003). Altruism and prosocial behavior. In T. Millon \& M. J. Lerner (Eds.), Handbook of psychology: Personality and Social Psychology, (pp. 463-484). Hoboken, NJ: John Wiley \& Sons Inc.

Bhattacharjee, S., Gopal, R. D., \& Lertwachara, K. (2006). Consumer Search and Retailer Strategies in the Presence of Online Music Sharing. Journal of Management Information Systems, 23(1), 129-159.

Bono, S., Rubin, A. Stubblefield, A. \& Green, M. (2006). Security Through Legality. Communications of the ACM, 49(6), 41- 43.

De Groot, J. I. M. \& Steg, L. (2010), Morality and nuclear energy: Perceptions of risks and benefits, personal norms, and willingness to take action related to nuclear energy, Risk Analysis, 30(9), 1363 - 1373. 


\section{Issues in Information Systems}

Volume 20, Issue 4, pp. 181-187, 2019

Eckhardt, A., Laumer, S., \& Weitzel, T. (2009). Who influences whom? Analyzing workplace referents' social influence on IT adoption and non-adoption. Journal of Information Technology, 24, 11-24.

Higgins, G.E., Fell, B.D, \& Wilson, A.L. (2007). Digital Piracy: Assessing the Contributions of an Integrated SelfControl Theory and Social Learning Theory Using Structural Equation Modeling. Criminal Justice Studies, 19(1), 3-22.

Hsu, C-L., \& Lu, H-P. (2004). Why do people play on-line games? An extended TAM with social influences and flow experience. Information \& Management, 41(7), 853-868.

Huijts, N. M. A., De Groot, J. I. M., Molin, E. J. E. \& van Wee, B. (2013). Intention to act towards a local hydrogen refueling facility: Moral considerations versus self-interest. Transport Research, 63-74.

Onwezen, M. C., Antonides, G. \& Bartels, J. (2013). The Norm Activation Model: An exploration of the functions of anticipated pride and guilt in pro-environmental behavior. Journal of Economic Psychology, 39, 141-153.

Peace, A.G., Galletta, D.F., and Thong, J.Y.L. (2003). Software piracy in the workplace: A model and empirical test, Journal of Management Information Systems, 20(1), 153 - 177.

Peters, A., Cutscher, H., and Scholz, R.W. (2011). Psychological determinants of fuel consumption of purchased new cars. Transportation Research Part F: Traffic Psychology and Behaviour, 14, 229-239.

Ringle, C.M., S. Wende, \& Will A. (2005). Smart PLS, U.o. Hamburg (ed.), University of Hamburg, Hamburg, Germany.

Schultz, P. W., Gouveia, V. V., Cameron, L. D., Tankha, G., Schmuck, P., \& Franek, M. (2005). Value and their relationship to environmental concern and conservation behavior. Journal of Cross-Cultural Psychology, 36, 457-475.

Schwartz, S. H. (1977). Normative Influences on altruism. In L. Berkowitz (Ed.), Advances in experimental social psychology (Vol. 10, pp. 221-279). New York: Academic Press.

Steg, L. \& de Groot, J. (2010). Explaining prosocial intentions: Testing causal relationships in the norm activation model. British Journal of Social Psychology, 49, 725 - 743.

Steg, L., Dreijerink, L., \& Abrahamse, W. (2005). Factors influencing the acceptability of energy policies: Testing VBN theory: Journal of Environmental Psychology, 25, 415-425.

Taylor, S.A., Ishida, C., \& Wallace, D. (2009). Intention to Engage in Digital Piracy: A Conceptual Model and Empirical Test. Journal of Service Research, 11(3), 246-262.

Trafimow, D. \& Finlay, K. A. (1996). The importance of subjective norms for a minority of people: Between-subjects and within-subjects. Personality and Social Psychology Bulletin, 22, 820-828.

Venkatesh, V., \& Morris, M. G. (2000). Why don't men ever stop to ask for directions? Gender, social influence, and their role in technology acceptance and usage behavior. MIS Quarterly, 24(1), 115-139.

Venkatesh, V., Morris, M., Davis, G., \& Davis, F. (2003). User Acceptance of Information Technology: Toward a Unified View. MIS Quarterly, 7(3), 425-478. 